\title{
Polar Aprotic Modifiers for Chromatographic Separation and Back-Exchange Reduction for Protein Hydrogen/Deuterium Exchange Monitored by Fourier Transform Ion Cyclotron Resonance Mass Spectrometry
}

\author{
Santosh G. Valeja, ${ }^{1}$ Mark R. Emmett, ${ }^{1,2}$ Alan G. Marshall ${ }^{1,2}$ \\ ${ }^{1}$ Department of Chemistry and Biochemistry, 95 Chieftain Way, Florida State University, Tallahassee, FL 32306, USA \\ ${ }^{2}$ Ion Cyclotron Resonance Program, National High Magnetic Field Laboratory, Florida State University, 1800 East Paul Dirac \\ Drive, Tallahassee, FL 32310-4005, USA
}

\begin{abstract}
Hydrogen/deuterium exchange monitored by mass spectrometry is an important non-perturbing tool to study protein structure and protein-protein interactions. However, water in the reversedphase liquid chromatography mobile phase leads to back-exchange of $\mathrm{D}$ for $\mathrm{H}$ during chromatographic separation of proteolytic peptides following $H / D$ exchange, resulting in incorrect identification of fast-exchanging hydrogens as unexchanged hydrogens. Previously, fast high-performance liquid chromatography (HPLC) and supercritical fluid chromatography have been shown to decrease back-exchange. Here, we show that replacement of up to $40 \%$ of the water in the LC mobile phase by the modifiers, dimethylformamide (DMF) and $\mathrm{N}$ methylpyrrolidone (NMP) (i.e., polar organic modifiers that lack rapid exchanging hydrogens), significantly reduces back-exchange. On-line LC micro-ESI FT-ICR MS resolves overlapped proteolytic peptide isotopic distributions, allowing for quantitative determination of the extent of back-exchange. The DMF modified solvent composition also improves chromatographic separation while reducing back-exchange relative to conventional solvent.
\end{abstract}

Key words: FT-ICR, FTMS, Myoglobin, Luteinizing hormone releasing hormone (LHRH)

\section{Introduction}

Tydrogen/deuterium exchange [1-6] coupled with mass 1 spectrometry has been widely used in structural biology to study protein structure and dynamics [7, 8], including folding and unfolding of proteins $[9,10]$, protein/

Electronic supplementary material The online version of this article (doi:10.1007/s13361-011-0329-z) contains supplementary material, which is available to authorized users.

Correspondence to: Alan G. Marshall; e-mail: MARSHALL@MAGNET. FSU.EDU protein interactions $[11,12]$, peptide/membrane complex interactions [13], conformational changes induced by ligand binding [14], and binding of small inhibitors [15]. The exchange rate of an amide hydrogen reflects solvent accessibility, which is in turn governed by secondary and tertiary structure. Protons involved in hydrogen bonding in an alpha-helix or beta-sheet exchange much slower than protons in unstructured regions or at the surface of a protein. The effect of primary structure including various amino acid side chains, $\mathrm{pH}$, and temperature has been systematically studied by Englander and co-workers [16-18]. Mass spectrometry is appropriate if the system is inaccessible by 
X-ray crystallography or NMR due to inability to crystallize and/or insolubility and/or too high molecular weight.

Previously, H/D exchange (HDX) monitored by mass spectrometry has been successfully applied to probe structural features of intact proteins including peptide binding [19] and conformational changes [20]. Enzymatic digestion of labeled protein into peptides (first shown by Rosa and Richards) [21] as well as a fragment separation method [22], followed by mass spectrometric analysis $[23,24]$ significantly enhances sensitivity and spatial resolution. The enzymatic digestion is typically carried out with pepsin [23] at low temperature $\left(0.1^{\circ} \mathrm{C}\right)$ and low $\mathrm{pH}(\mathrm{pH} \sim 2.3)$ [3] to minimize the loss of incorporated deuterium. Recently, we have confirmed the advantages of protease type XIII [25] for enhanced digestion efficiency, more efficient electrospray ionization, and higher sequence resolution [26]. Hence, all digestions were performed with protease XIII.

Previously, we have shown reduced back-exchange with a shorter sub-2-micron stationary phase (ProZap $\mathrm{C}_{18}$ resin, Grace/Vydac) and fast chromatography (1.5 min gradient) [27]. This methodology resulted in an average backexchange of $22 \%$ relative to conventional reversed-phase chromatography (RPLC) with a $\mathrm{C}_{5}$ column that averaged $30 \%$ back-exchange [12]. High-resolution Fourier transform ion cyclotron resonance mass spectrometry (FT-ICR MS) analysis [28] greatly aids in the interpretation of the complex spectra due to the fast chromatography. Supercritical chromatography (SFC) also dramatically reduces back-exchange in HDX experiments [29], but short column life has limited its use. Back-exchange associated with matrix-assisted laser desorption ionization is high due to the additional sample preparation step to introduce the matrix [30,31]. The extent of back-exchange depends on peptide sequence [18,32], duration of exposure to solvents with exchangeable hydrogens [27], temperature, $\mathrm{pH}[3,16]$, and choice of chromatographic medium [33].

The present goal is to further reduce back-exchange during the HDX experiment by replacement of $\mathrm{H}_{2} \mathrm{O}$ in the aqueous mobile phase with polar aprotic modifiers [dimethylformamide (DMF) or $N$-methylpyrrolidone (NMP)] during the HPLC step. The mobile phase modifiers, DMF and NMP, cannot contribute to backexchange due to the lack of rapidly exchangeable hydrogens in their structures. Minimizing the concentration of protic solvent with these aprotic modifiers should thus significantly reduce back-exchange due to reduced exposure to $\mathrm{H}_{2} \mathrm{O}$. Organic solvents have been historically shown to decrease the amide hydrogen exchange rate of proteins, most likely due to peptide bond solvation effects and decrease in acid dissociation constant of water, $\mathrm{K}_{\mathrm{w}}$ (due to lower $\left[\mathrm{OH}^{-}\right]$concentration) $[22,34]$ to reduce tritium losses in HPLC fragment separation [22]. Englander and co-workers demonstrated progressive shift in $\mathrm{pH}_{\min }(\mathrm{H} / \mathrm{D}$ exchange rate) to higher $\mathrm{pH}$ with increase in concentration of co-solvents such as methanol, acetonitrile, tetrahydrofuran (THF), and dioxane, by use of a spectrometric method based on acetamide [22]. In this report, our goal is to replace protic water in reversed-phase aqueous buffer with a significantly polar aprotic modifier (THF and dioxane are not suitable in buffer A here due to higher elution strength, i.e., poor retention of peptides) to enable acceptable salt separation, peptide retention, and back-exchange reduction with electrospray ionization (ESI) [35] detected by FT-ICR MS. DMF/DMSO have been shown to increase the solubility of hydrophobic compounds and are used in electrospray ionization (ESI) [35] of peptides and sugars [36]. We have recently demonstrated the use of these modifiers for enhanced charging and improved chromatographic separation of intact proteins with higher sensitivity [37]. DMF and dimethylacetamide (DMAA) has been used to significantly improve recovery of tryptic peptides and yield higher sequence coverage in in-gel digestion protocols for protein identification. The increase in protocol efficiency is attributed to the higher solubility of peptides in those solvents [38, 39]. In addition to their MS compatibility, the solvents tested in this paper, DMF and NMP, were chosen for their ability to solubilize H/D exchange buffer, peptides, and proteins. We also compare various RPLC columns with respect to speed and chromatographic separation for complex protein mixtures.

\section{Experimental}

\section{Materials}

Dimethylformamide, $N$-methylpyrrolidone, equine heart myoglobin, protease type XIII from Aspergillus saitoi, formic acid, deuterium oxide, and luteinizing hormone releasing hormone (LHRH) were obtained from SigmaAldrich (St. Louis, MO, USA). HPLC grade water and acetonitrile were purchased from J.T. Baker (Philipsburg, NJ, USA). Sodium phosphate (monobasic and dibasic) was purchased from Fisher Biotech (Fairlawn, New Jersey, USA).

\section{Hydrogen/Deuterium Exchange and Digestion}

The entire HDX experiment was automated with a LEAP robot (HTS PAL; Leap Technologies, Carrboro, NC, USA) [40]. A blank control, in which the protein or peptide sample under study was diluted in $\mathrm{H}_{2} \mathrm{O}$ buffer instead of $\mathrm{D}_{2} \mathrm{O}$, provides a reference point for deuterium incorporation analysis. Stock solution concentrations were: $80 \mu \mathrm{M}$ myoglobin, $\sim 40 \mu \mathrm{M}$ FKBP, and $100 \mu \mathrm{M}$ LHRH. Stock myoglobin solution $(5 \mu \mathrm{L})$ was diluted 1:10 into $50 \mathrm{mM}$ sodium phosphate buffer (monobasic and dibasic) in $\mathrm{D}_{2} \mathrm{O}(\mathrm{pH}$ meter reading=7.8). HDX incubation periods were $1,8,30 \mathrm{~min}$, and $2 \mathrm{~h}$. All 
HDX incubations were performed in triplicate. Each HDX reaction was simultaneously digested and quenched with an equal volume of protease XIII $[25,26]$ in $2 \%$ formic acid for $2 \mathrm{~min}$, and a final $\mathrm{pH}$ of $\sim 2.5$. The digested sample was then injected onto a reversed-phase $\mathrm{C}_{18}$ HPLC column to desalt and separate peptides. The entire HDX process was performed at $0.4{ }^{\circ} \mathrm{C}$ controlled by a Huber recirculating water bath (Peter Huber, Offenburg, Germany).

As a separate control that did not require proteolysis, $100 \mu \mathrm{M}$ LHRH was diluted 1:10 into sodium phosphate buffer in $\mathrm{D}_{2} \mathrm{O}$ for $5 \mathrm{~min}$ to initiate $\mathrm{H} / \mathrm{D}$ exchange. The reaction was then immediately quenched by adding $2 \%$ formic acid and decreasing the temperature to $\sim 0.4{ }^{\circ} \mathrm{C}$. The sample was injected onto a Jupiter $\mathrm{C}_{18}$ column for desalting with a 1.5 min gradient $(2 \% \mathrm{~B}-95 \% \mathrm{~B})$ as described below. The average mass of LHRH for each experiment was calculated, and back-exchange was determined as explained elsewhere [27].

\section{On-Line LC ESI FT-ICR MS and Data Analysis}

A Jasco HPLC/SFC instrument (Jasco, Easton, MD, USA) was interfaced to a LEAP robot (HTS PAL; Leap Technologies, Carrboro, NC, USA) to desalt and separate the HDX peptides after proteolysis. Three LC platforms were compared: Jupiter $\mathrm{C}_{18}$ column (Phenomenex, Torrance, CA, USA; $1 \times 50 \mathrm{~mm}, 5 \mu \mathrm{m}$ particle size, $300 \AA$ pore size), HALO $\mathrm{C}_{18}$ column (MAC-MOD Analytical Inc., PA, USA; $2.1 \times 50 \mathrm{~mm}, 2.7 \mu \mathrm{m}, 90 \AA$ pore size), and ProZap $\mathrm{C}_{18}$ column (Grace Davidson, Deerfield, IL, USA; $2.1 \times 10 \mathrm{~mm}$, HR, $1.5 \mu \mathrm{m}, 500 \AA$ pore size). The HPLC gradient (including the loading period for salt separation), data acquisition period, and flow rate with each of various columns is shown in Supplementary Figure S1. Briefly, the gradient was $2 \% \mathrm{~B}$ to $95 \% \mathrm{~B}$ in $1.5 \mathrm{~min}$ [27] ( $\mathrm{A}: \mathrm{H}_{2} \mathrm{O}$ :DMF: formic acid, $60: 40: 0.5 \mathrm{vol} / \mathrm{vol} / \mathrm{vol}$; B: acetonitrile:DMF: formic acid, 98:2:0.5 vol $/ \mathrm{vol} / \mathrm{vol}$ ) at $50 \mu \mathrm{L} / \mathrm{min}$ with a Jupiter $\mathrm{C}_{18}$ column. NMP was also tested in the same proportion as DMF. The results were compared to conventional HPLC solvent (A: $\mathrm{H}_{2} \mathrm{O}$ :acetonitrile:formic acid, 98:2:0.5 vol/ $/ \mathrm{vol} / \mathrm{vol} ; \mathrm{B}: \mathrm{H}_{2} \mathrm{O}$ :acetonitrile:formic acid, 2:98:0.5 $\mathrm{vol} / \mathrm{vol} / \mathrm{vol})$. A post-column splitter reduced the eluent flow to $\sim 400-500 \mathrm{~nL} / \mathrm{min}$ for efficient microelectrospray ionization [41].

The LC eluent was microelectrosprayed into a custombuilt 14.5 T FT-ICR mass spectrometer [42] equipped with front-end modified hybrid linear quadrupole ion trap (LTQ-FT; Thermo Fisher Corp., Bremen, Germany) [43, 44]. It is imperative to optimize front-end parameters for non-volatile modifiers. Higher capillary temperature $\left(275^{\circ} \mathrm{C}\right)$ and tube lens voltage $(190 \mathrm{~V})$ yielded enhanced desolvation and better ion mobility and transmission. Data was collected with Xcalibur 2.0 software (Thermo Fisher). FT-ICR mass spectra were acquired at high mass resolving power $\left(\mathrm{m} / \Delta \mathrm{m}_{50 \%}=200,000\right.$ at $\mathrm{m} / \mathrm{z} \quad 400$, in which $\Delta \mathrm{m}_{50 \%}$ denotes mass spectral peak full width at half-maximum peak height). The total data acquisition period for each sample varied from $5 \mathrm{~min}$ (ProZap, $300 \mu \mathrm{L} / \mathrm{min}$ ) to $10 \mathrm{~min}$ (Jupiter, $50 \mu \mathrm{L} / \mathrm{min}$ ), depending on the chromatographic column and the flow rate (Figure S1). External ion accumulation [45] was performed in the front-end linear ion trap with a target ion population of three million charges for each FT-ICR acquisition. LTQ-accumulated ions were transferred $(\sim 1 \mathrm{~ms})$ through three octopole ion guides $\left(2.2 \mathrm{MHz}, 250 \mathrm{~V}_{p-p}\right)$ to a capacitively coupled [46] open cylindrical ICR cell (55 $\mathrm{mm}$ i.d.) for analysis. The robust automatic gain control [43] for transferring the same number of ions for each FT-ICR MS scan coupled with the high magnetic field [47] provides excellent external calibration mass accuracy (typically better than $500 \mathrm{ppb}$ rms).

Data was analyzed with custom software [48] permitting reliable peptide isotopic distribution and charge state identification. The software also accurately computes the number of deuteriums incorporated into each proteolytic peptide segment for each $\mathrm{H} / \mathrm{D}$ exchange period, relative to the blank control (no $\mathrm{D}_{2} \mathrm{O}$ ).

\section{Back-Exchange Calculations}

Fragments common to conventional and modified mobile phases for each chromatographic column are identified. Relative back-exchange for a common peptide is then calculated for each $\mathrm{D}_{2} \mathrm{O}$ incubation period separately (1, $8,30 \mathrm{~min}$, and $2 \mathrm{~h}$ ) for modifiers relative to conventional protic solvent (higher back-exchange). Then, we calculate average back-exchange (higher deuterium level) for that specific peptide for all incubation periods and finally compute the global relative average back-exchange percentage for all common peptides, taking into account retention time differences due to altered chromatographic selectivity with less polar modifiers relative to water [49-51].

\section{Results and Discussion}

\section{Solubility Comparisons for New Mobile Phase Modifiers}

Solubility and retention of solute on the stationary phase media are two of the most basic requirements for HPLC. We therefore began by determining precipitation for sodium phosphate buffer (monobasic and dibasic) and LHRH $(10 \mu \mathrm{M})$ as a function of DMF and NMP concentration. Table 1 shows structure, viscosity, and polarity of these modifiers. At $40 \%$ (vol $/ \mathrm{vol}$ ) the modifiers were compatible with the HDX buffer and peptides; higher concentration resulted in precipitation of salts and peptides at $0{ }^{\circ} \mathrm{C}$. Therefore, $40 \%$ of the water could be replaced by DMF or NMP in the HPLC separation step. DMSO is a common NMR solvent because it can 
Table 1. Structure, Polarity, and Viscosity of Polar Aprotic Solvents Relative to Water and Acetonitrile

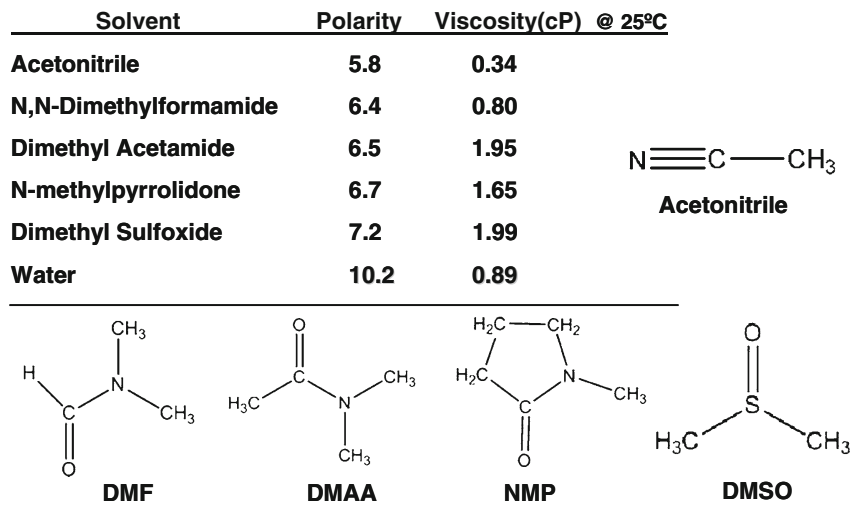

solubilize both hydrophobic and hydrophilic compounds. However, DMSO and DMAA are not suitable for chromatography due to their high viscosity, higher back pressure during HPLC separation, and reduction in electrospray ionization (ESI) efficiency at $0{ }^{\circ} \mathrm{C}$.

\section{LHRH Retention on a Reversed-Phase LC Column with DMF-Modifier (UV Detection)}

To confirm that peptides are retained by the reversed-phase column, $20 \mu \mathrm{L}$ of LHRH $(50 \mu \mathrm{M})$ was injected onto a Jupiter $\mathrm{C}_{18}$ column (Shimadzu HPLC system) at room temperature, with UV detection at $214 \mathrm{~nm}$ with a $10 \mathrm{~min}$ gradient (2\% B-95\% B) at a flow rate of $50 \mu \mathrm{L} / \mathrm{min}$. LHRH was retained for $\sim 6.5 \mathrm{~min}$ with conventional solvent (10 $\mathrm{min}$ gradient, $2 \%-95 \%$ organic), $\sim 1.5 \mathrm{~min}$ with conventional solvent (isocratic flow at $70 \%$ acetonitrile), and $\sim 3$ min with DMF-modified solvent (10 min gradient, data not shown). Hence, LHRH is clearly retained on the chromatographic column with DMF-modifier.

\section{Back-Exchange Tested with LHRH}

Preliminary back-exchange studies were conducted with LHRH, pyroGlu-His-Trp-Ser-Tyr-Gly-Leu-Arg-Pro-Gly$\mathrm{CONH}_{2}$, a decapeptide. The number of potentially exchangeable amide hydrogens for LHRH is nine (minus one for proline and plus one for the pyroGlu N-terminus), for total of nine backbone amide hydrogens and maximum of 19 potentially exchangeable hydrogens (including side chains). The deuterium incorporation for $5 \mathrm{~min}$ exchange period serves to establish the relative back-exchange level between different solvent systems. $100 \mu \mathrm{M}$ LHRH $(10 \mu \mathrm{L})$ was incubated in $90 \mu \mathrm{L} \mathrm{D} \mathrm{D}_{2} \mathrm{O}$ buffer (1:10 dilution) for $5 \mathrm{~min}$ followed by $1: 1$ quenching with $2 \%$ formic acid (in $\mathrm{H}_{2} \mathrm{O}$, no protease present, sham digestion) for $2 \mathrm{~min}$. A $30 \mu \mathrm{L}$ aliquot was injected onto a Jupiter $\mathrm{C}_{18}$ HPLC column for desalting under identical conditions with conventional, DMF- and
NMP-modified solvents at $50 \mu \mathrm{L} / \mathrm{min}$. The average mass of LHRH $\left(\mathrm{M}_{\mathrm{avg}}\right)$ was computed from

$$
\mathrm{M}_{\text {avg }=} \Sigma\left(\mathrm{M}_{\mathrm{i}} \mathrm{I}_{\mathrm{i}}\right) / \Sigma \mathrm{I}_{\mathrm{i}}
$$

in which $\mathrm{M}_{\mathrm{i}}$ is the mass of the $\mathrm{i}^{\text {th }}$ peak in the isotopic distribution and $\mathrm{I}_{\mathrm{i}}$ is its relative abundance. NMP produced the highest back pressure ( 12 $\mathrm{MPa}, 1740 \mathrm{psi})$ followed by DMF $(\sim 9 \mathrm{MPa}, 1305$ psi) and conventional solvents $(\sim 5 \mathrm{MPa}, 725 \mathrm{psi})$ at $98 \% \mathrm{~A}$ and $2 \% \mathrm{~B}$ mobile phase composition. LHRH exhibited shorter retention time with modifiers ( $\sim 5.2$ min with DMF and $\sim 5.4$ min with NMP) relative to conventional solvents $(\sim 6.2 \mathrm{~min})$. The spectrum with the highest signal-to-noise ratio was used to calculate the average mass of LHRH. The average number of incorporated deuteriums is simply the increase in LHRH average mass in Da. The DMF-modified solvent system exhibited the highest D level and hence, the least backexchange relative to conventional and NMP-modified systems (Table 2).

\section{Higher Deuterium Level with DMF or NMP on Jupiter $C_{18}$}

We aim to minimize back-exchange by modifying only the chromatographic conditions because most back-exchange occurs post-digestion/quench, during the HPLC separation step [27]. Given that LHRH showed higher deuterium level (due in part to earlier elution) by replacement of $40 \%$ of protic $\mathrm{H}_{2} \mathrm{O}$ by aprotic DMF/NMP modifiers, we proceeded to deuterate myoglobin and separate protease XIII fragments on a Jupiter $\mathrm{C}_{18}$ column with modified and unmodified solvents. A longer gradient yields more efficient chromatographic separation, but at the cost of significantly higher back-exchange due to longer retention $[12,27]$. Consequently, in order to minimize back-exchange, we perform fast chromatographic separation (1.5 min short gradient), and employ ultrahigh resolution FT-ICR MS to address the resultant spectral complexity, thereby achieving significantly higher deuterium level [27] due to less exposure to water. Here, salts reproducibly elute from $\sim 1.5$ to 2.8 min followed by peptides at $95 \%$ buffer B (only $5 \%$ aqueous phase to minimize back-exchange) [27]. Table 3 shows the myoglobin digest results after separation with conventional, DMF-, and NMP-modified solvents with a $1.5 \mathrm{~min}$ gradient $(1 \mathrm{~min}$ loading period). With DMF, more and longer fragments (on average) were observed than for the other two solvent systems. Surprisingly, the protease XIII fragments were retained longer with modifiers than with conventional solvent [37] at low temperature, presumably due to higher back pressure caused by the high viscosity of these modifiers as well as inter- and intra-molecular hydrogen bonding. Nevertheless, the deuterium level was higher for the fragments eluted with modifiers due to less exposure to $\mathrm{H}_{2} \mathrm{O}$. Enhanced chromatographic separation between salts and smaller hydrophilic peptides was achieved by slight 
Table 2. Effect of Modified Solvents on LHRH Back-exchange After 5 min Incubation in $\mathrm{D}_{2} \mathrm{O}$ Followed by Elution from a Jupiter $\mathrm{C}_{18}$ Column at $50 \mu \mathrm{L} / \mathrm{min}$

\begin{tabular}{lccc}
\hline Solvent system & $\begin{array}{c}\text { LHRH number-average } \\
\text { mass }(\mathrm{Da})^{\mathrm{a}}\end{array}$ & $\begin{array}{c}\text { No. of incorporated } \\
\text { deuteriums }\end{array}$ & $\begin{array}{c}\text { \% Decrease in back-exchange relative } \\
\text { to conventional HPLC solvent }\end{array}$ \\
\hline Conventional & 1186.616 & 4.47 & - \\
DMF-modified & 1187.522 & 5.38 & 20.36 \\
NMP-modified & 1187.093 & 4.95 & 10.73 \\
\hline
\end{tabular}

${ }^{\mathrm{a}}$ LHRH number-average mass without exchange $=1182.141 \mathrm{Da}$.

modification of loading condition gradient [i.e., washing for 1 min (Table 3) rather than 0.5 min (Supplementary Table S1)] with $98 \%$ solvent $\mathrm{A}$ with a subsequent increase in fragment number, higher sequence coverage, and decrease in average peptide length.

Figure 1 shows the charge state distribution for myoglobin digest protease XIII fragments. Fewer protease XIII fragments were observed with NMP for all charge states greater than $2+$. Singly and doubly charged peptide fragments were more abundant than those of higher charge states.

Deuterium level with modifiers was compared with that for conventional solvents for each of the HDX incubation periods for individual fragments, and average higher deuterium level was computed for all identical fragments. Average deuterium level for four identical representative myoglobin digest peptide fragments was significantly higher ( $\sim 22 \%$ and $\sim 11 \%$ ) with DMF (Figure 2$)$ and NMP-modified solvents (Supplemental Information, Figure S2). Fragments retained longer in the presence of modifiers ([1-11] and [94106]) also show higher deuterium level. We discounted the use of NMP for further high speed separation due to fewer fragments, lower deuterium level, higher back pressure, and longer retention time relative to DMF modifier. Interestingly, only 26 common fragments were found with conventional solvent (99 total fragments) and DMF-modified solvent (109 total fragments) (see below).

\section{Higher Deuterium Level with HALO $C_{18}$ than Jupiter $C_{18}$}

We then tested two HALO $\mathrm{C}_{18}$ columns (30 and $50 \mathrm{~mm}$ length). HALO is a fast separation resin because of its smaller particle size $(2.7 \mu \mathrm{m}$ and its porous shell $[0.5 \mu \mathrm{m}])$ that reduces solute diffusion path and minimizes axial dispersion. The claimed result is a higher number of theoretical plates and better separation at higher flow rate. Table 3. Results of Protease XIII Digestion of Myoglobin, for Three Different Solvent Systems (1 min Loading Period)

\begin{tabular}{lcccc}
\hline Solvent system & $\begin{array}{c}\text { No. of } \\
\text { fragments }\end{array}$ & $\begin{array}{c}\text { Sequence } \\
\text { coverage }\end{array}$ & $\begin{array}{c}\text { Average } \\
\text { length }\end{array}$ & $\begin{array}{c}\text { Elution time } \\
\text { for peptide } \\
\text { fragments (min) }\end{array}$ \\
\hline Conventional & 99 & $100 \%$ & 12 & $3.3-6.6$ \\
DMF-modified & 109 & $94 \%$ & 17 & $3.9-7.2$ \\
NMP-modified & 77 & $97 \%$ & 15 & $4.7-7.8$ \\
\hline
\end{tabular}

The shorter HALO $\mathrm{C}_{18}$ column gave poor separation with $40 \%$ DMF and was not pursued.

Supplemental Figure S3 presents a total ion chromatogram for myoglobin digest peptide fragments separated by conventional and 40\% DMF-modified solvents with a longer HALO $\mathrm{C}_{18}$ column at $150 \mu \mathrm{L} / \mathrm{min}$ flow rate. Peptides elute gradually with improved separation over a wider window with DMF modified solvent composition (4.2 $\mathrm{min})$ relative to conventional solvents $(1.3 \mathrm{~min})$. Moreover, more proteolytic fragments are observed with DMF modifier system. The Halo $\mathrm{C}_{18}$ column coupled with the DMF-modified solvents yielded $\sim 31 \%$ higher average deuterium level than conventional solvent for 34 common proteolytic fragments. The average deuterium level was $\sim 20 \%$ higher for the HALO $\mathrm{C}_{18}$ column relative to the Jupiter $\mathrm{C}_{18}$ column with DMF due to higher flow rate $(150 \mu \mathrm{L}$ versus $50 \mu \mathrm{L})$ and concomitant reduced retention time.

\section{Highest Deuterium Level with ProZap $C_{18}$ Column and DMF Modifier}

The ProZap $\mathrm{C}_{18}$ column, due to its wide i.d., short length, small particle size, and large pore size has demonstrated ultrafast peptide separations at $300 \mu \mathrm{L} / \mathrm{min}$ [27]. The ProZap $\mathrm{C}_{18}$ column with $40 \%$ DMF resulted in high back-pressure ( $>25 \mathrm{MPa}$ ) [52] and could not be used. Poor separation was noted even at a lower flow rate. However, $20 \%$ DMF in the mobile phase resulted in an acceptable separation at $300 \mu \mathrm{L} /$ min at a permissible back-pressure $(\sim 17 \mathrm{MPa}, 2465$ psi with DMF-modified solvent versus $\sim 10 \mathrm{MPa}, 1450$ psi with conventional solvent) at $98 \%$ A and $2 \%$ B mobile phase composition. Figure 3 illustrates elution profiles for myoglobin digest peptide fragments with a ProZap $\mathrm{C}_{18}$ column with conventional and DMF-modified solvents. Consistent with the HALO column, DMF modified solvent composition/polarity results in selective elution and improved separation ( $2 \mathrm{~min}$ versus $30 \mathrm{~s})$ of proteolytic fragments and subsequent higher fragment number (Table S2). Peptides elute gradually with the modified solvent system and some peptides exhibit shorter retention time relative to conventional solvents (Table S2), further minimizing exposure to $\mathrm{H}_{2} \mathrm{O}$.

Figure 4 shows deuterium level profiles for four representative myoglobin digest peptides for conventional and DMF-modified solvents. Fragments retained for similar/ longer time in the presence of DMF also show significantly 

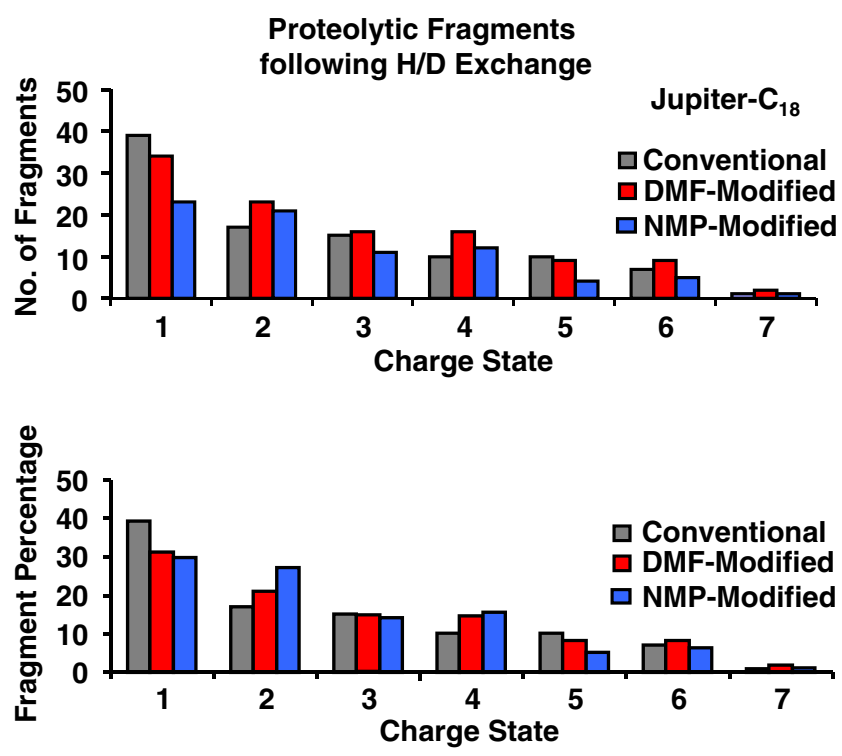

Figure 1. Number (top) and percentage (bottom) charge state distributions of proteolytic peptides from myoglobin following $\mathrm{H} / \mathrm{D}$ exchange, for conventional, DMF-modified, and NMPmodified HPLC solvents with a 1.5 min gradient. Note that DMF-modified solvent produces more fragments at charge states higher than $2+$ than conventional or NMP-modified solvents. The higher charge states from the DMF-modified solvents also exhibit slightly longer fragments (Table 3)

higher deuterium incorporation (lower back-exchange) due to fewer exchangeable solvent hydrogens. Myoglobin frag- ments show $\sim 19 \%$ average higher deuterium level among 45 identical fragments with the DMF-modified solvent.

Figure 5 indicates deuterium levels for various myoglobin digest fragments after $30 \mathrm{~min}$ (top) and $2 \mathrm{~h}$ (bottom) exchange period, and subsequent separation with HALO (150 $\mu \mathrm{L} / \mathrm{min})$ and ProZap $(300 \mu \mathrm{L} / \mathrm{min}) \mathrm{C}_{18}$ columns for conventional and DMF-modified solvents. DMF incorporation reduces back-exchange with both columns. Fragments separated with the ProZap column with 20\% DMF show the highest deuterium level due to overall early elution ( $\sim 2.5 \mathrm{~min}$ ) relative to the HALO column ( $\sim 6 \mathrm{~min})$ due to faster flow rate and shorter column length.

Likewise, HDX of $40 \mu \mathrm{M}$ FKBP (human recombinant [C22A] FK506-binding protein, $\sim 12 \mathrm{kDa}$ ) also exhibited $\sim 18 \%$ higher average deuterium level with DMF-modified solvent (Supplementary Figure S4) among 38 identical fragments. Furthermore, consistent with our myoglobin results, we observe higher fragment number (118 versus 99) along with selective elution of FKBP fragments with DMF (0.7-2.3 min) relative to fast elution with conventional solvents (1.7-2.0 min). The elution profiles are different due to the overall polarity: i.e., rate of change of the solvent composition (DMF and $\mathrm{H}_{2} \mathrm{O}$ ), not just due to the added modifier.

We previously showed that the ProZap $\mathrm{C}_{18}$ column yielded the then-lowest back-exchange level of 22\% [27]. By further replacing $\mathrm{H}_{2} \mathrm{O}$ with $20 \%$ aprotic $\mathrm{DMF}$ and ultrafast separation, we reduce average back-exchange by further $\sim 19 \%$ (of $22 \%$ ) to a final back-exchange level of

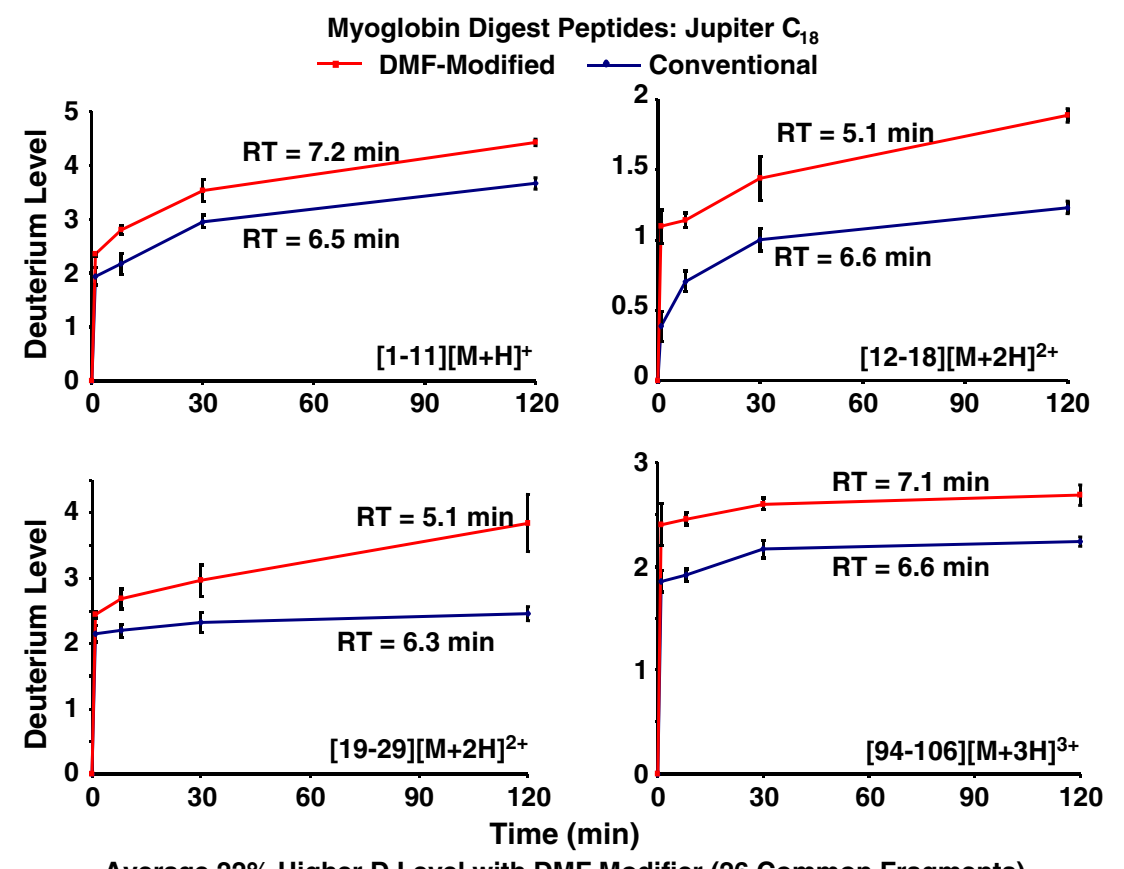

Average 22\% Higher D Level with DMF Modifier (26 Common Fragments)

Figure 2. Deuterium level profiles for four selected proteolytic peptides from myoglobin. DMF-modified HPLC solvent resulted in $\sim 22 \%$ higher average deuterium level than with conventional solvent. The retention time for each peptide fragment with DMF (shown above the curve) and conventional (shown below) clearly indicates higher deuterium level with aprotic modifier due not to early elution, but to partial removal of protic solvent. Error bars represent variation among triplicate experiments 


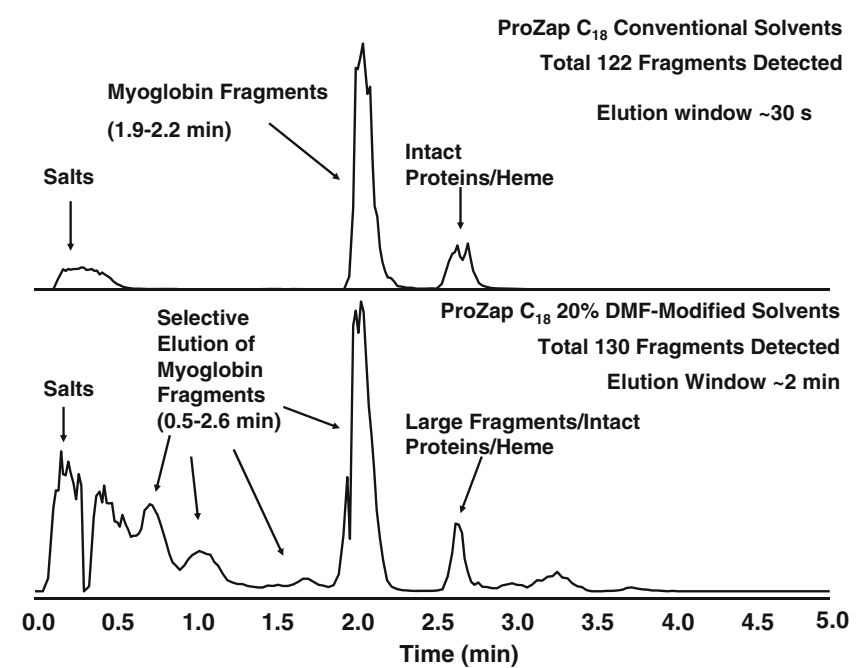

Figure 3. Total ion chromatogram for myoglobin digest proteolytic fragments with a ProZap $\mathrm{C}_{18}$ column for conventional and $20 \%$ DMF modifiers. The overall change in the polarity of solvent mixture results in improved chromatographic separation, more proteolytic fragments, and reduced back-exchange after DMF addition

$\sim 18 \%$, the lowest yet achieved with HPLC ESI FT-ICR MS. Moreover, fast chromatography with the short ProZap column results in overall faster elution of peptides (fewer total mass spectral scans: memory storage) for more efficient data reduction and also allows more time for the column to fully re-equilibrate for better reproducibility relative to other longer columns.
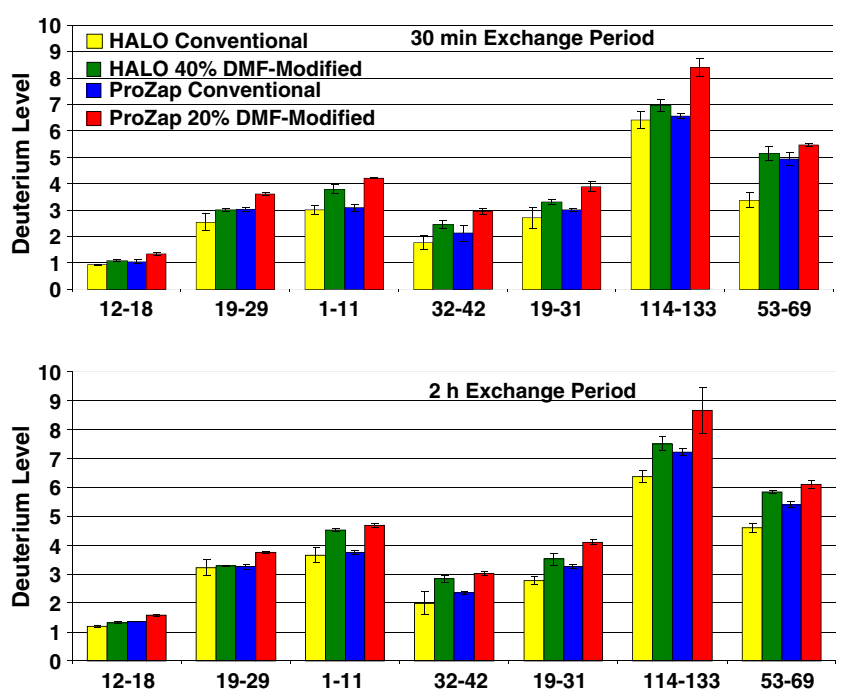

Figure 5. Deuterium level for myoglobin peptides after exchange for $30 \mathrm{~min}$ (top) and $2 \mathrm{~h}$ (bottom) and separation with HALO $\mathrm{C}_{18}$ and ProZap $\mathrm{C}_{18}$ columns with a short (1.5 min) gradient; $20 \%$ DMF modifier with ProZap column yields the highest deuterium level and subsequent lowest back-exchange due to superfast elution at $300 \mu \mathrm{L} / \mathrm{min}$, short column length, and lack of exchangeable protons. Error bars represent variation among triplicate experiments

\section{Modifiers Affect Chromatographic Separation, ESI, and Detection}

Conventional and DMF-modified mobile phase with different columns yielded $\sim 30 \%-40 \%$ identical fragments. The
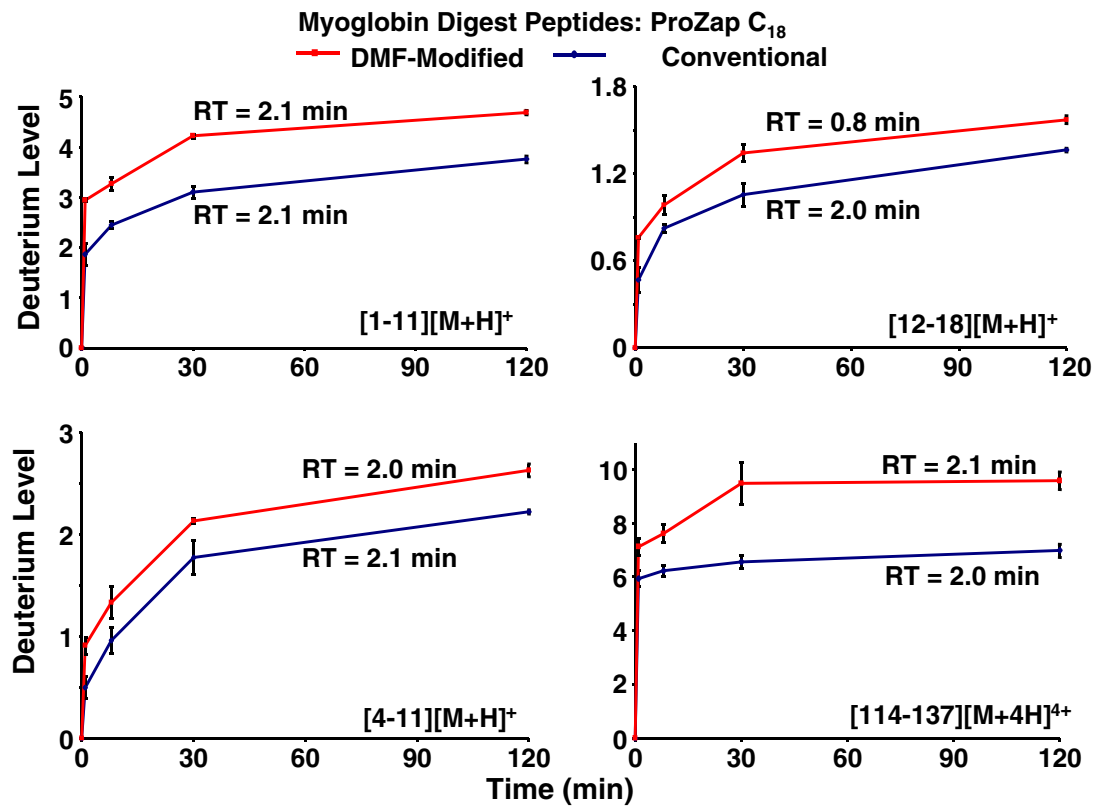

Average 19\% Higher D Level with DMF Modifier (45 Common Fragments)

Figure 4. Deuterium level profiles as for Figure 2, for four representative proteolytic peptides from myoglobin separated with a ProZap $\mathrm{C}_{18}$ column and $20 \%$ DMF-modifier. Peptides retained for similar time show less back-exchange due to lack of exchangeable protons in the mobile phase with DMF. The final back-exchange level of $\sim 18 \%$ is the lowest ever reported for $\mathrm{H} /$ D exchange monitored by HPLC ESI FT-ICR mass spectrometry 
new fragments may be attributed to the reduced polarity of DMF/NMP relative to water, changing chromatographic separation and elution time. Peptides selectively elute from the column over a wider window depending on their affinity and partition characteristics with modifiers, versus small window (30 s) with conventional solvents. A given peptide may elute to yield only 1 or 2 mass spectral acquisitions with ultra-fast ProZap column and conventional solvent due to the steep elution gradient, but spread over $\sim 4$ to 5 acquisitions with DMF. Consequently, a wider elution window (gradual elution) considerably increases peptide detection for FT-ICR MS (1 acquisition/s), accounting for the higher proteolytic fragment number for DMF modified solvent system for both myoglobin and FKBP for all tested columns due to improved elution efficiency. Moreover, gradual elution is advantageous for ESI [35], due to fewer ionization interferences. Finally, physico-chemical properties of solvents reportedly affect charging during ESI under denaturing [53-56] and non-denaturing [57, 58] conditions. Indeed, we have recently characterized DMF/NMP and other modifiers for charge enhancement of intact proteins with improved sensitivity and chromatography [37]. Higher boiling point modifiers (DMF/NMP) may affect ionization by altering analyte distribution [59] in the ESI droplet, resulting in different peptide mapping. In addition, the previously reported enhanced solvating power of DMF for hydrophobic peptides [36, 38, 39] could result in different peptide maps. We are continuing to investigate the effects of modifiers on individual peptide fragment retention and backexchange (sequence dependence); origin of longer retention time for some fragments [37]; improved LC separation; and applicability to higher molecular weight proteins.

\section{Conclusion}

We previously demonstrated that fast chromatographic separations could reduce total back-exchange to $\sim 22 \%$ [27]. Replacing $\mathrm{H}_{2} \mathrm{O}$ with polar aprotic modifiers further reduces back-exchange and improves chromatographic separation of peptide fragments applicable for HDX. Replacement of $\mathrm{H}_{2} \mathrm{O}$ with $20 \%$ aprotic DMF in the chromatography solvent, coupled with fast chromatographic separation, reduces average back-exchange to $\sim 18 \%$, the lowest yet achieved in published HDX experiments. In addition, the overall polarity of the solvent system with aprotic modifiers increases the number of observable protease XIII proteolytic peptides (even with fast chromatography), for more detail about protein conformational changes upon ligand or protein binding, post-translational modifications, or mutagenesis, and mapping of contact surfaces in protein complexes.

\section{Acknowledgments}

The authors thank Jeremiah D. Tipton and Hui-min Zhang for their support in instrumentation and useful discussions. This work was supported by NIH (R01 GM78359), NSF
Division of Materials Research through DMR-06-54118, and the State of Florida.

\section{References}

1. Linderstrom-Lang, K.U.: Deuterium exchange between peptides and water. Chem Soc Spec Publ 2, 1 (1955)

2. Hvidt, A., Nielsen, S.O.: Hydrogen exchange in proteins. Adv. Protein Chem. 21, 287-386 (1966)

3. Englander, S.W., Poulsen, A.: Hydrogen-tritium exchange of the randon chain polypeptide. Biopolymers 7, 379-393 (1969)

4. Englander, S.W.: Hydrogen exchange and mass spectrometry: a historical perspective. J. Am. Soc. Mass Spectrom. 17, 1481-1489 (2006)

5. Engen, J.R.: Analysis of protein conformation and dynamics by hydrogen/deuterium exchange MS. Anal. Chem. 81, 7870-7875 (2009)

6. Marcsisin, S.R., Engen, J.R.: Hydrogen exchange mass spectrometry: what is it and what can it tell us? Anal. Bioanal. Chem. 397, 967-972 (2010)

7. Scholtz, J.M., Robertson, A.D.: Hydrogen exchange techniques. Methods Mol. Biol. 40, 291-311 (1995)

8. Englander, S.W., Sosnick, T.R., Englander, J.J., Mayne, L.: Mechanisms and uses of hydrogen exchange. Curr. Opin. Struct. Biol. 6, 1823 (1996)

9. Engen, J.R., Smith, D.L.: Investigating protein structure and dynamics by hydrogen exchange MS. Anal. Chem. 73, 256A-265A (2001)

10. Konermann, L., Simmons, D.A.: Protein-folding kinetics and mechanisms studied by pulse-labeling and mass spectrometry. Mass Spectrom. Rev. 22, 1-26 (2003)

11. Mandell, J.G., Falick, A.M., Komives, E.A.: Identification of proteinprotein interfaces by decreased amide proton solvent accessibility. Proc. Natl. Acad. Sci. U. S. A. 95, 14705-14710 (1998)

12. Lam, T.T., Lanman, J.K., Emmett, M.R., Hendrickson, C.L., Marshall, A.G., Prevelige, P.E.: Mapping of protein-protein contact surfaces by hydrogen/deuterium exchange, followed by on-line high-performance liquid chromatography-electrospray ionization fourier-transform ioncyclotron-resonance mass analysis. J. Chromatogr. A 982, 85-95 (2002)

13. Demmers, J.A.A., Haverkamp, J., Heck, A.J.R., Koeppe, R.E., Killian, J.A.: Electrospray ionization mass spectrometry as a tool to analyze hydrogen/deuterium exchange kinetics of transmembrane peptides in lipid bilayers. Proc. Natl. Acad. Sci. U. S. A. 97, 31893194 (2000)

14. Wang, F., Li, W., Emmett, M.R., Hendrickson, C.L., Marshall, A.G., Zhang, Y.L., Wu, L., Zhang, Z.Y.: Conformational and dynamic changes of yersinia protein tyrosine phosphatase induced by ligand binding and active site mutation and revealed by H/D exchange and electrospray ionization fourier transform ion cyclotron resonance mass spectrometry. Biochemistry 37, 15289-15299 (1998)

15. Brier, S., Lemaire, D., DeBonis, S., Kozielski, F., Forest, E.: Use of hydrogen/deuterium exchange mass spectrometry and mutagenesis as a tool to identify the binding region of inhibitors targeting the human mitotic kinesin Eg5. Rapid Commun. Mass Spectrom. 20, 456-462 (2006)

16. Molday, R.S., Englander, S.W., Kallen, R.G.: Primary structure effects on peptide group hydrogen exchange. Biochemistry 11, 150-158 (1972)

17. Englander, S.W., Kallenbach, N.R.: Hydrogen exchange and structural dynamics of proteins and nucleic-acids. Q. Rev. Biophys. 16, 521-655 (1984)

18. Bai, Y., Milne, J.S., Mayne, L., Englander, S.W.: Primary structure effects on peptide group hydrogen exchange. Proteins 17, 75-86 (1993)

19. Kragelund, B.B., Robinson, C.V., Knudsen, J., Dobson, C.M., Poulsen, F.M.: Folding of a four-helix bundle: studies of acyl-coenzyme a binding protein. Biochemistry 34, 7217-7224 (1995)

20. Wagner, D.S., Anderegg, R.J.: Conformation of cytochrome c studied by deuterium exchange-electrospray ionization mass spectrometry. Anal. Chem. 66, 706-711 (1994)

21. Rosa, J.J., Richards, F.M.: An Experimental Procedure for Increasing the Structural Resolution of Chemical Hydrogen-Exchange Measurements on Proteins: Application to Ribonuclease S Peptide. J. Mol. Biol. 133, 399-416 (1979)

22. Englander, J.J., Rogero, J.R., Englander, S.W.: Protein hydrogen exchange studied by the fragment separation method. Anal. Biochem. 147, 234-244 (1985) 
23. Zhang, Z., Smith, D.L.: Determination of amide hydrogen exchange by mass spectrometry: a new tool for protein structure elucidation. Protein Sci. 2, 522-531 (1993)

24. Smith, D.L., Deng, Y., Zhang, Z.: Probing the noncovalent structure of proteins by amide hydrogen exchange and mass spectrometry. J. Mass Spectrom. 32, 135-146 (1997)

25. Cravello, L., Lascoux, D., Forest, E.: Use of different proteases working in acidic conditions to improve sequence coverage and resolution in hydrogen/deuterium exchange of large proteins. Rapid Commun. Mass Spectrom. 17, 2387-2393 (2003)

26. Zhang, H.-M., Kazazic, S., Schaub, T.M., Tipton, J.D., Emmett, M.R., Marshall, A.G.: Enhanced digestion efficiency, peptide ionization efficiency, and sequence resolution for protein hydrogen/deuterium exchange monitored by FT-ICR mass spectrometry. Anal. Chem. 80, 9034-9041 (2008)

27. Zhang, H.-M., Bou-Assaf, G.M., Emmett, M.R., Marshall, A.G.: Fast reversed-phase liquid chromatography to reduce back exchange and increase throughput in H/D exchange monitored by FT-ICR mass spectrometry. J. Am. Soc. Mass Spectrom. 20, 520-524 (2009)

28. Marshall, A.G., Hendrickson, C.L., Jackson, G.S.: Fourier transform ion cyclotron resonance mass spectrometry: a primer. Mass Spectrom. Rev. 17, 1-35 (1998)

29. Emmett, M.R., Kazazic, S., Marshall, A.G., Chen, W., Shi, S.D., Bolanos, B., Greig, M.J.: Supercritical fluid chromatography reduction of hydrogen/deuterium back exchange in solution-phase hydrogen/ deuterium exchange with mass spectrometric analysis. Anal. Chem. 78, 7058-7060 (2006)

30. Mandell, J.G., Falick, A.M., Komives, E.A.: Measurement of amide hydrogen exchange by MALDI-TOF mass spectrometry. Anal. Chem. 70, 3987-3995 (1998)

31. Kipping, M., Schierhorn, A.: Improving hydrogen/deuterium exchange mass spectrometry by reduction of the back-exchange effect. J. Mass Spectrom. 38, 271-276 (2003)

32. Wales, T.E., Engen, J.R.: Hydrogen exchange mass spectrometry for the analysis of protein dynamics. Mass Spectrom. Rev. 25, 158-170 (2006)

33. Wu, Y., Kaveti, S., Engen, J.R.: Extensive deuterium back-exchange in certain immobilized pepsin columns used for H/D exchange mass spectrometry. Anal. Chem. 78, 1719-1723 (2006)

34. Woodward, C.K., Ellis, L.M., Rosenberg, A.: The solvent dependence of hydrogen exchange kinetics of folded proteins. J. Biol. Chem. 250, 440-444 (1975)

35. Fenn, J.B., Mann, M., Meng, C.K., Wong, S.F., Whitehouse, C.M.: Electrospray ionization for mass spectrometry of large biomolecules. Science 246, 64-71 (1989)

36. Szabo, P.T., Kele, Z.: Electrospray mass spectrometry of hydrophobic compounds using dimethyl sulfoxide and dimethylformamide as solvents. Rapid Commun. Mass Spectrom. 15, 2415-2419 (2001)

37. Valeja, S.G., Tipton, J.D., Emmett, M.R., Marshall, A.G.: New reagents for enhanced liquid chromatographic separation and charging of intact protein ions for electrospray ionization mass spectrometry. Anal. Chem. 82, 7515-7519 (2010)

38. Soskic, V., Godovac-Zimmermann, J.: Improvement of an in-gel tryptic digestion method for matrix-assisted laser desorption/ionization-time of flight mass spectrometry peptide mapping by use of volatile solubilizing agents. Proteomics 1, 1364-1367 (2001)

39. Methogo, R.M., Dufresne-Martin, G., Leclerc, P., Leduc, R., Klarskov, $\mathrm{K}$.: Mass spectrometric peptide fingerprinting of proteins after western blotting on polyvinylidene fluoride and enhanced chemiluminescence detection. J. Proteome Res. 4, 2216-2224 (2005)

40. Kazazic, S., Nilsson, C.L., Emmett, M.R., Marshall, A.G.: Proceedings of the 5th North American FT-ICR Mass Spectrometry Conference. Key West, Florida (2005)

41. Emmett, M.R., Caprioli, R.M.: Micro-electrospray mass spectrometry: ultra-high-sensitivity analysis of peptides and proteins. J Am. Soc. Mass Spectrom. 5, 605-613 (1994)
42. Schaub, T.M., Hendrickson, C.L., Horning, S., Quinn, J.P., Senko, M. W., Marshall, A.G.: High-performance mass spectrometry: fourier transform ion cyclotron resonance at 14.5. Tesla Anal Chem 80 , 3985-3990 (2008)

43. Schwartz, J.C., Senko, M.W., Syka, J.E.: A two-dimensional quadrupole ion trap mass spectrometer. J. Am. Soc. Mass Spectrom. 13, 659669 (2002)

44. Syka, J.E., Marto, J.A., Bai, D.L., Horning, S., Senko, M.W., Schwartz, J.C., Ueberheide, B., Garcia, B., Busby, S., Muratore, T., Shabanowitz, J., Hunt, D.F.: Novel linear quadrupole ion trap/Ft mass spectrometer: performance characterization, and use in the comparative analysis of histone H3 post-translational modifications. J. Proteome Res. 3, 621626 (2004)

45. Senko, M.W., Hendrickson, C.L., Emmett, M.R., Shi, S.D.H., Marshall, A.G.: External accumulation of ions for enhanced electrospray ionization fourier transform ion cyclotron resonance mass spectrometry. J. Am. Soc. Mass Spectrom. 8, 970-976 (1997)

46. Beu, S.C., Laude, D.A.: Elimination of axial ejection during excitation with a capacitively coupled open trapped-ion cell for fourier-transform ion-cyclotron resonance mass-spectrometry. Anal. Chem. 64, 177-180 (1992)

47. Marshall, A.G., Guan, S.: Advantages of high magnetic field for fourier transform ion cyclotron resonance mass spectrometry. Rapid Commun. Mass Spectrom. 10, 1819-1823 (1996)

48. Kazazic, S., Zhang, H.-M., Schaub, T.M., Emmett, M.R., Hendrickson, C.L., Blakney, G.T., Marshall, A.G.: Automated data reduction for hydrogen/deuterium exchange experiments, enabled by high-resolution fourier transform ion cyclotron resonance mass spectrometry. J. Am. Soc. Mass Spectrom. 21, 550-558 (2010)

49. Glajch, J.L., Kirkland, J.J., Squire, K.M., Minor, J.M.: Optimization of solvent strength and selectivity for reversed-phase liquid chromatography using an interactive mixture-design statistical technique. $J$. Chromatogr. A 199, 57-79 (1980)

50. Snyder, L.R., Quarry, M.A., Glajch, J.L.: Solvent-strength selectivity in reversed-phase HPLC. Chromatographia 24, 33-44 (1987)

51. Roses, M., Canals, I., Allemann, H., Siigur, K., Bosch, E.: Retention of ionizable compounds on HPLC. 2. Effect of $\mathrm{pH}$, ionic strength, and mobile phase composition on the retention of weak acids. Anal. Chem. 68, 4094-4100 (1996)

52. Góra, R., Hutta, M., Vrìka, M., Katuìcák, S., Jablonský, M.: Characterization of Klason Lignins by reversed-phase high-performance liquid chromatography using wide-pore Octadecylsilica and stepwise gradients of dimethylformamide in water. J. Sep. Sci. 29, 2179-2189 (2006)

53. Iavarone, A.T., Jurchen, J.C., Williams, E.R.: Effects of solvent on the maximum charge state and charge state distribution of protein ions produced by electrospray ionization. J. Am. Soc. Mass Spectrom. 11, 976-985 (2000)

54. Iavarone, A.T., Jurchen, J.C., Williams, E.R.: Supercharged protein and peptide ions formed by electrospray ionization. Anal. Chem. 73, 1455$1460(2001)$

55. Iavarone, A.T., Williams, E.R.: Mechanism of charging and supercharging molecules in electrospray ionization. J. Am. Chem. Soc. 125, 2319-2327 (2003)

56. Sterling, H.J., Williams, E.R.: Origin of supercharging in electrospray ionization of noncovalent complexes from aqueous solution. J. Am. Soc. Mass Spectrom. 20, 1933-1943 (2009)

57. Lomeli, S.H., Yin, S., Ogorzalek Loo, R.R., Loo, J.A.: Increasing charge while preserving noncovalent protein complexes for ESI-MS. $J$. Am. Soc. Mass Spectrom. 20, 593-596 (2009)

58. Lomeli, S.H., Peng, I.X., Yin, S., Loo, R.R., Loo, J.A.: New reagents for increasing ESI multiple charging of proteins and protein complexes. J. Am. Soc. Mass Spectrom. 21, 127-131 (2010)

59. Cech, N.B., Enke, C.G.: Relating electrospray ionization response to nonpolar character of small peptides. Anal. Chem. 72, 2717-2723 (2000) 